\title{
Voluntary task switching under load: Contribution of top-down and bottom-up factors in goal-directed behavior
}

\author{
Jelle Demanet, Frederick Verbruggen, \\ BAPTIST LIEFOOGHE, AND ANDRÉ VANDIERENDONCK \\ Ghent University, Ghent, Belgium
}

\begin{abstract}
The present study investigated the relative contribution of bottom-up and top-down control to task selection in the voluntary task-switching (VTS) procedure. In order to manipulate the efficiency of top-down control, a concurrent working memory load was imposed during VTS. In three experiments, bottom-up factors, such as stimulus repetitions, repetition of irrelevant information, and stimulus-task associations, were introduced in order to investigate their influence on task selection. We observed that the tendency to repeat tasks was stronger under load, suggesting that top-down control counteracts the automatic tendency to repeat tasks. The results also indicated that task selection can be guided by several elements in the environment, but that only the influence of stimulus repetitions depends on the efficiency of top-down control. The theoretical implications of these findings are discussed within the interplay between top-down and bottom-up control that underlies the voluntary selection of tasks.
\end{abstract}

Many researchers assume that goal-directed behavior relies on the intentional and controlled activation of task goals (Baddeley, 1992; Logan \& Gordon, 2001; Miller \& Cohen, 2001). However, several studies have demonstrated that task goals can also be activated automatically by information in the environment (e.g., Mattler, 2003; Mayr \& Bryck, 2007; Verbruggen \& Logan, 2009) or by the retrieval of previously formed associations between a stimulus and a particular goal (e.g., Verbruggen \& Logan, 2008; Waszak, Hommel, \& Allport, 2003). In the present study, we examined the contribution of top-down and bottom-up activation of task goals in voluntary task switching (VTS).

In VTS, participants switch between cognitive tasks. They are free to select the task to perform, as long as each task is selected an approximately equal number of times and participants do not follow a predictable pattern of task selection (Arrington, 2008; Arrington \& Logan, 2004, 2005; Liefooghe, Demanet, \& Vandierendonck, 2009; Mayr \& Bell, 2006). A general finding is that participants repeat tasks more often than they switch (Arrington \& Logan, 2005). This task-repetition bias has been linked to the efficiency of top-down control processes involved in the voluntary selection of task goals. For example, Mayr and Bell argued that participants tend to repeat tasks because the task on the previous trial is still the most active one when a new task is selected. In order to overcome this bias, the activated task has to be inhibited. Thus, selection of tasks would depend on topdown control processes (see also Arrington \& Logan,
2004, 2005). However, several studies have shown that bottom-up processes also contribute to task selection in VTS (e.g., Arrington, 2008), and Mayr and Bell observed that the task-repetition bias was stronger when the stimulus of the previous trial was repeated than when the stimulus alternated. This stimulus-repetition effect suggests that voluntary task selection is not completely immune to bottom-up priming effects.

In the present study, we focused on the contribution of top-down control and bottom-up priming in voluntary task selection. Studies in several paradigms have shown that bottom-up factors contribute more to behavior in cognitively demanding situations (for a review, see Lavie, 2005). A manipulation that is often used to reduce the efficiency of top-down control is a concurrent working memory (WM) load (e.g., Logan, 2007). To test the relative contribution of bottom-up and top-down processes in task selection, we manipulated WM load in the VTS paradigm in three experiments. Each experiment consisted of two conditions: a load condition and a no-load condition (see Logan, 2007). In the load condition, participants were shown six letters that they had to remember (study phase), followed by 13 voluntary switch trials (VTS phase), followed by a recall phase, in which participants had to indicate which letters they had been shown in the study phase. In the no-load condition, the study phase was immediately followed by the recall phase, which, in turn, was followed by the VTS phase, so that there was no concurrent memory load during the test phase. We predicted that bottom-up control would con-

J. Demanet, jelle.demanet@ugent.be 
tribute more to task selection in the load condition than in the no-load condition. The results of Experiment 1 confirmed this prediction and showed that the stimulusrepetition effects and the task-repetition bias were stronger in the load condition than in the no-load condition. In Experiments 2 and 3, we further tested how stimulus repetitions affected task-selection processes. We propose three accounts for the stimulus-repetition effect. First, the effect could be caused by the repetition of visual information on the screen, which could prime the decision to repeat the task (see also Arrington \& Logan, 2005). Second, the effect could be caused by the retrieval of associations formed between the stimulus and the task executed on the previous trial. When the stimulus repeats, this association is retrieved, and the task goal of the previous trial is primed (see, e.g., Verbruggen \& Logan, 2008). Third, the effect could be due to the retrieval of associations between the stimulus and the task-execution response (see, e.g., Hommel, 1998; Soetens, 1998). When the stimulus repeats, the task-execution response of the previous trial is also repeated. This suggests that participants would not select a new task first; instead, they would directly execute a response. Experiments 2 and 3 were designed to test these accounts by including repetitions of task-irrelevant features in Experiment 2 and forming strong stimulus-task associations in a training phase in Experiment 3.

\section{METHOD}

\section{Participants and Materials}

Eighty students from Ghent University participated for course requirements and credit (in Experiment 1, $N=24$; in Experiment 2, $N=24$; in Experiment 3, $N=32$ ). The participants were tested individually by means of a Pentium III personal computer with a 17-in. color monitor running Tscope (Stevens, Lammertyn, Verbruggen, \& Vandierendonck, 2006). We used an external response box with four buttons to register responses in the VTS phase and a QWERTY keyboard to register responses in the recall phase.

\section{Procedure}

The experimental session of Experiment 1 consisted of a study phase, a recall phase, and a VTS phase. In the study phase, we presented six different low-interconfusable consonants (for details, see Vandierendonck, De Vooght, \& Van der Goten, 1998). The consonants were presented in the center of the screen at a rate of one item per second (500 msec on, $500 \mathrm{msec}$ off). In the recall phase, participants had to recall the memorized items in the correct order and type the items on the keyboard. There were no time constraints in the recall phase. In the VTS phase, participants categorized a stimulus as being smaller or larger than 5 (magnitude task) or odd or even (parity task). We used digits 1 through 9, excluding 5 . The magnitude task (smaller, left-outer button; larger, left-inner button) and the parity task (odd, right-inner button; even, right-outer button) were mapped on a different hand. The task-to-hand assignment was counterbalanced across participants. There were 13 trials in the VTS phase. Each trial started with the presentation of a stimulus. When a response was executed or the maximal response time (RT) of 3,000 msec had elapsed, a fixed response-stimulus interval of $100 \mathrm{msec}$ started. The first trial was a filler; of the remaining 12 trials, $4(25 \%)$ were stimulus repetitions. The experimental session started with three practice blocks, in which participants practiced (1) the study and recall phases separately, (2) the VTS phase separately, and (3) the combination of the three phases. Before the practice blocks, we presented Arrington and Logan's (2004) instructions (in Dutch) on the screen and paraphrased them when necessary. The practice trials were followed by the experimental session, which consisted of 20 lists per condition: load condition, study-test-recall; no-load condition, study-recall-test. The order of the conditions was counterbalanced across participants. The experimental session lasted approximately $30 \mathrm{~min}$.

Experiment 2 was identical to Experiment 1, except that, in the VTS phase, stimulus repetitions were excluded. Instead, we presented a task-irrelevant shape on each trial. The target stimulus appeared inside one of four white, nonfilled shapes (circle, triangle, hexagon, square; each shape $=5.9 \mathrm{~cm}^{2}$ ). On $25 \%$ of the trials, the shape of the previous trial was repeated.

In Experiment 3, participants performed either an animacy task (nonliving or living) or a size task (smaller or larger than a basketball) on nouns. We selected 128 nouns on the bases of word frequency (average frequency $=11.0$ per million) and word length (average length $=5.6$ letters). For every participant, three different stimulus sets of 32 nouns were selected (matched for frequency and word length). All sets consisted of 8 large living, 8 small living, 8 large nonliving, and 8 small nonliving stimuli. Before the experimental session, participants performed a training session of 16 single-task blocks ( $\pm 40 \mathrm{~min}$ ). In the training session, the first stimulus set was always used for the animacy task, and the second stimulus set was always used for the size task. Participants practiced one task in the odd-numbered blocks and one in the even-numbered blocks. Task-to-block mapping was counterbalanced. Each training block consisted of 32 trials, and each item of the relevant set was presented once. All of the trials in the training session started with the presentation of a noun in the center of the screen. This stimulus remained on the screen for $1,000 \mathrm{msec}$, regardless of the RT. The maximal RT was $4,000 \mathrm{msec}$, and the response-stimulus interval was $750 \mathrm{msec}$. The participants responded orally by saying [bu:] for

Table 1

Task-Repetition Proportions As a Function of Load,

Trial Type, and Task Transition for Experiments 1 and 2

\begin{tabular}{|c|c|c|c|c|c|c|c|c|}
\hline \multirow[b]{3}{*}{ Trial Type } & \multicolumn{4}{|c|}{ No Load } & \multicolumn{4}{|c|}{ Load } \\
\hline & \multicolumn{2}{|c|}{$\begin{array}{c}\text { Task } \\
\text { Repetitions }\end{array}$} & \multicolumn{2}{|c|}{$\begin{array}{c}\text { Task } \\
\text { Switches }\end{array}$} & \multicolumn{2}{|c|}{$\begin{array}{c}\text { Task } \\
\text { Repetitions }\end{array}$} & \multicolumn{2}{|c|}{$\begin{array}{c}\text { Task } \\
\text { Switches } \\
\end{array}$} \\
\hline & $M$ & $S E$ & $M$ & $S E$ & $M$ & $S E$ & $M$ & $S E$ \\
\hline \multicolumn{9}{|c|}{ Experiment 1} \\
\hline Stimulus repetitions & .48 & .04 & .52 & .04 & .62 & .04 & .38 & .04 \\
\hline Stimulus alternations & .48 & .02 & .52 & .02 & .54 & .02 & .46 & .02 \\
\hline \multicolumn{9}{|c|}{ Experiment 2} \\
\hline Shape repetitions & .55 & .02 & .45 & .02 & .59 & .03 & .41 & .03 \\
\hline Shape alternations & .51 & .03 & .49 & .03 & .55 & .02 & .45 & .02 \\
\hline
\end{tabular}


Table 2

Task-Selection Proportions As a Function of Load, Trial Type, and Task for Experiment 3

\begin{tabular}{|c|c|c|c|c|c|c|c|c|}
\hline \multirow[b]{3}{*}{ Trial Type } & \multicolumn{4}{|c|}{ No Load } & \multicolumn{4}{|c|}{ Load } \\
\hline & \multicolumn{2}{|c|}{$\begin{array}{c}\text { Animacy } \\
\text { Task }\end{array}$} & \multicolumn{2}{|c|}{ Size Task } & \multicolumn{2}{|c|}{$\begin{array}{c}\text { Animacy } \\
\text { Task }\end{array}$} & \multicolumn{2}{|c|}{ Size Task } \\
\hline & $M$ & $S E$ & $M$ & $S E$ & $M$ & $S E$ & $M$ & $S E$ \\
\hline Animacy & .54 & .02 & .46 & .02 & .57 & .02 & .43 & .02 \\
\hline Size & .46 & .02 & .54 & .02 & .46 & .02 & .54 & .02 \\
\hline Neutral & .51 & .02 & .49 & .02 & .49 & .01 & .51 & .01 \\
\hline
\end{tabular}

living, [bi:] for nonliving, [ba:] for small, and [bo:] for large. The structure of the experimental phase of Experiment 3 was similar to that of Experiment 1. Because VTS stimuli were words, the WM load consisted of six different numbers (range $=1-9$ ). There were no other differences in the study or recall phase. In the VTS phase, the animacy task was performed with one hand (nonliving, left-outer button; living, left-inner button) and the size task with the other hand (small, right-inner button; large, right-outer button). Eight lists of VTS trials were used in both load conditions. In each VTS phase, 12 stimuli were presented: 4 stimuli of the animacy set, 4 stimuli of the size set, and 4 stimuli of the third stimulus set (i.e., the neutral set, which was not used in the training phase). The maximal RT in the VTS trials was 5,000 msec because the tasks were more difficult than those in Experiments 1 and 2.

\section{RESULTS AND DISCUSSION}

The first trial of each VTS phase and the trials following an error were discarded (for Experiment 1, data loss = $12.8 \%$; for Experiment 2, data loss $=11.5 \%$; for Experiment 3 , data loss $=12.3 \%$ ). In this study, we were interested in the processes involved in the voluntary selection of tasks. Therefore, in the Results section, we will focus on task-choice data only. Analyses of response latencies are presented in the Appendix. The task-selection proportions appear in Tables 1 and 2. Analysis results appear in Tables 3 and 4.

The data from Experiment 1 were analyzed by means of a repeated measures ANOVA with load (no load vs. load) and trial type (stimulus repetition vs. stimulus alternation) as factors, performed on the task-repetition proportions. When relevant, individual $t$ tests were performed to test whether proportions were different from .50. As is shown in Tables 1 through 4, participants repeated the task of the previous trial more often in the load condition $(M=.579$,

Table 3

Outcome of the ANOVAs Conducted on the Selection Proportions of Task Repetitions for Experiments 1 and 2

\begin{tabular}{lcccc}
\hline \multicolumn{1}{c}{ Factor } & \multicolumn{1}{c}{$M S_{\mathrm{e}}$} & $d f$ & $F$ & $\eta_{\mathrm{p}}^{2}$ \\
\hline \multicolumn{4}{c}{ Experiment 1} \\
Load & .0118 & 1,23 & $18.70^{*}$ & .45 \\
Trial type & .0254 & 1,23 & 1.41 & .06 \\
Load $\times$ trial type & .0034 & 1,23 & $12.96^{*}$ & .36 \\
& \multicolumn{7}{c}{ Experiment 2 } \\
Load & .0045 & 1,23 & $7.46^{*}$ & .24 \\
Trial type & .0027 & 1,23 & $10.84^{*}$ & .32 \\
Load $\times$ trial type & .0025 & 1,23 & 0.00 & .00 \\
\hline${ }^{*} p<.05$. & & &
\end{tabular}

$S E=.029)$ [comparison .50: $t(23)=2.68, p=.01]$ than in the no-load condition $(M=.483, S E=.026)$ [comparison .50: $t(23)=-0.66, p=.51]$. These results confirm the hypothesis that top-down control is needed to counteract the tendency to repeat tasks (e.g., Mayr \& Bell, 2006). The absence of a tendency (in comparison with .50) to repeat tasks in the no-load condition is probably due to the length of the sequences. This result converges with the findings of Rapoport and Budescu (1997), indicating that, in random selection of events, there is a greater tendency to alternate for shorter sequences.

It is important to note that we observed a stimulusrepetition effect in the load condition, but not in the noload condition, of Experiment 1 (see Tables 1 and 3). Simple main effects showed that the effect of trial type was significant in the load condition $[F(1,23)=4.93$, $\left.M S_{\mathrm{e}}=.0163, \eta_{\mathrm{p}}^{2}=.18\right]$, but not in the no-load condition $(F<1)$. This suggests that bottom-up control contributes more to task selection in cognitively demanding situations (i.e., the load condition) than in less demanding situations (i.e., the no-load condition). The complete absence of a stimulus-repetition effect in the no-load condition is probably due to the relatively low number of stimulus repetitions (see also Experiments 3 and 4 in Arrington \& Logan, 2005).

The data from Experiment 2 were analyzed by means of a repeated measures ANOVA with load (no load vs. load) and trial type (shape repetition vs. shape alternation) as factors. The analyses showed that tasks were repeated more often in the load condition $(M=.570, S E=.024)$ [comparison $.50: t(23)=2.91, p=.01]$ than in the no-load condition $(M=.532, S E=.023)[$ comparison $.50: t(23)=1.41, p=$ .17]. Furthermore, tasks were repeated more often on shape repetitions $(M=.569, S E=.022)$ than on shape alternations $(M=.534, S E=.024)$, which suggests that repeating visual information can prime task repetitions. However, the size of the shape-repetition effect was comparable for the load and the no-load conditions (see Table 1). The absence of an interaction suggests that the stimulus-repetition effect observed in Experiment 1 was not simply caused by the repetition of visual information on the screen.

The data from Experiment 3 were analyzed in two steps. First, we examined whether task selections were influenced by the training phase by means of a repeated measures ANOVA with load and stimulus set (animacy vs. size vs. neutral set) as factors. We focused on the proportions of the animacy task; we would get symmetrical results if the focus was on the size task. The analysis showed that there was a strong learning effect (see Table 2). Contrasts showed that the animacy task was selected more often for the animacy set $(M=.554, S E=.012)$ than for the neutral set $(M=.501, S E=.010)[F(1,31)=$ $\left.10.31, M S_{\mathrm{e}}=.0088, \eta_{\mathrm{p}}^{2}=.25\right]$ or the $\operatorname{size} \operatorname{set}(M=.458$, $S E=.011)\left[F(1,31)=28.57, M S_{\mathrm{e}}=.0104, \eta_{\mathrm{p}}^{2}=.48\right]$. The difference between the size and neutral sets was also significant $\left[F(1,31)=7.94, M S_{\mathrm{e}}=.0074, \eta_{\mathrm{p}}^{2}=.20\right]$, which suggests that participants tended to choose the size task for the size set. Combined, these findings suggest that learned stimuli primed the selection of the task they were associated with in the training phase. However, this 
Table 4

Outcome of the ANOVAs Conducted on the Animacy Task-Selection Proportions for Experiment 3

\begin{tabular}{lcccc}
\multicolumn{1}{c}{ Factor } & Wilks & $d f$ & $F$ & $\eta_{\mathrm{p}}^{2}$ \\
\hline Load & .9986 & 1,31 & 0.04 & .00 \\
Trial type & .5204 & 2,30 & $13.83^{*}$ & .48 \\
Load $\times$ trial type & .9390 & 2,30 & 0.98 & .06 \\
\hline${ }^{*} p<.05$. & & & &
\end{tabular}

stimulus-priming effect was similar in the no-load and load conditions (Table 2). The absence of an interaction shows that stimulus-task associations did not cause the priming effect seen in Experiment 1.

In a second step, we examined whether there was an influence of load on the general task-repetition bias, as was the case in the other experiments. We analyzed taskrepetition proportions with a one-way ANOVA with load as the only factor. Consistent with the findings in Experiments 1 and 2, tasks were repeated more often in the load $(M=.517, S E=.021)$ [comparison $.50: t(32)=$ $0.81, p=.42]$ than in the no-load $(M=.472, S E=.020)$ [comparison .50: $t(32)=-1.44, p=.16 ; F(1,31)=6.55$, $\left.M S_{\mathrm{e}}=.0050, \eta_{\mathrm{p}}^{2}=.17\right]$ condition. Again, this finding shows task-repetition bias to be stronger in cognitively demanding situations.

\section{Recall Phase}

The proportions of correct recall represent the probability that a particular item was remembered correctly in the correct order. We analyzed the proportions by means of a simple main effects ANOVA with load as the only factor. As shown in Table 5, proportions were higher in the noload than in the load condition, which can be explained by the different order of the VTS and recall phases.

\section{Conclusion}

In the present study, we examined how bottom-up and top-down processes contribute to voluntary selection of tasks in situations that are cognitively demanding. In Experiment 1 , we found that participants repeated tasks more often in the load (demanding) condition than in the noload (nondemanding) condition. We replicated this load effect in Experiments 2 and 3. The effect of load on the task-repetition bias was consistent with the idea that topdown processes are necessary to overcome the tendency to repeat the same task. It also fits with the idea that topdown control inhibits the most recently executed task, and

Table 5

Mean Proportions of Correct Recall in the No-Load and Load Conditions and the Results of the Main Effect ANOVAs on These Proportions With Load As the Only Factor

\begin{tabular}{|c|c|c|c|c|c|c|c|c|}
\hline \multirow[b]{2}{*}{ Experiment } & \multicolumn{2}{|c|}{ No Load } & \multicolumn{2}{|c|}{ Load } & \multicolumn{4}{|c|}{ Main Effect Load } \\
\hline & $M$ & $\overline{S E}$ & $M$ & $\overline{S E}$ & $d f$ & $F$ & $M S_{\mathrm{e}}$ & $\eta_{\mathrm{p}}^{2}$ \\
\hline 1 & .93 & .1 & .84 & .2 & 1,23 & $42.80^{*}$ & .0025 & .65 \\
\hline 2 & .91 & .1 & .84 & .2 & 1,23 & $31.74^{*}$ & .0020 & .58 \\
\hline 3 & .97 & .1 & .83 & .3 & 1,31 & $27.36^{*}$ & .0101 & .47 \\
\hline
\end{tabular}

thus reduces the tendency to repeat tasks (Mayr \& Bell, 2006; see also Lien \& Ruthruff, 2008).

In Experiment 1, we found that stimulus repetitions elicited more task repetitions in the load than in the no-load condition. This observation seems to support the idea that bottom-up control contributes more to task selection in cognitively demanding situations (for a similar idea, see Arrington, 2008; Lavie, 2005). In Experiments 2 and 3, however, we observed priming effects of repeating shapes and acquired stimulus-task associations, but these effects did not interact with load. This suggests that some bottomup-driven effects occur independently of the cognitive demands of the situation. Furthermore, the results of Experiments 2 and 3 suggest that the stimulus-repetition effect, which was observed in Experiment 1 and interacted with load, was not caused by the repetition of visual information or the retrieval of stimulus-task associations. Instead, we propose that the stimulus-repetition effect is caused by the retrieval of associations between the stimulus and the task-execution response. When the stimulus is repeated, the task-execution response of the previous trial is activated and executed again. Interestingly, this suggests that, on a proportion of the trials, a response is executed without advance selection of a new task. The interaction with load in Experiment 1 suggests that there are more nonselection trials when top-down control is degraded in highly demanding situations. In less demanding situations, however, top-down processes can counteract this response-repetition tendency. This suggests that an important function of top-down control in VTS is to protect task selection from automatically triggered responses. This function of top-down control can be related to the response-inhibition account of Hübner and Druey (2006), which states that, in a task-switching context, a response has to be inhibited in order to avoid its automatic reexecution on the following trial (for a similar idea, see Logan \& Gordon, 2001). In this perspective, the present study contributes by showing that, when a response is inhibited less efficiently in a high-demanding situation, the chance to reexecute this response on the next trial is increased on stimulus repetitions. In sum, the present study shows that different bottom-up factors can guide task selection and that top-down control is necessary to shield task selection from the effects of stimulus-response associations and to counteract the tendency to perseverate tasks.

In conclusion, the data of the present study also allowed us to formulate an answer to the question, What is really voluntary or intentional in the VTS paradigm? We obtained convincing evidence for the ideas that task goals are automatically triggered by factors in the environment (e.g., Waszak et al., 2003) and that participants can inhibit recently activated task goals and suppress automatically triggered responses to protect intentional goal-directed behavior. Thus, perhaps the intentional or voluntary act in VTS is not to activate what is "willed" but to suppress what is "unwilled."

\section{AUTHOR NOTE}

F.V. is a postdoctoral fellow of the Research Foundation Flanders (FWO-Vlaanderen). We thank the reviewers for their comments on a 
previous version of the manuscript. Correspondence concerning this article should be addressed to J. Demanet, Department of Experimental Psychology, Ghent University, Henri Dunantlaan, 2, B-9000 Gent, Belgium (e-mail: jelle.demanet@ugent.be).

\section{REFERENCES}

Allport, A., \& Wylie, G. (2000). Task switching, stimulus-response bindings, and negative priming. In S. Monsell \& J. Driver (Eds.), Control of cognitive processes: Attention and performance XVIII (pp. 35 70). Cambridge, MA: MIT Press.

Arrington, C. M. (2008). The effect of stimulus availability on task choice in voluntary task switching. Memory \& Cognition, 36, 991997. doi:10.3758/MC.36.5.991

Arrington, C. M., \& Logan, G. D. (2004). Episodic and semantic components of the compound-stimulus strategy in the explicit taskcuing procedure. Memory \& Cognition, 32, 965-976.

Arrington, C. M., \& Logan, G. D. (2005). Voluntary task switching: Chasing the elusive homunculus. Journal of Experimental Psychology: Learning, Memory, \& Cognition, 31, 683-702. doi:10.1037/0278 $-7393.31 .4 .683$

BADDEley, A. [D.] (1992). Working memory. Science, 255, 556-559. doi:10.1126/science. 1736359

Hommel, B. (1998). Event files: Evidence for automatic integration of stimulus-response episodes. Visual Cognition, 5, 183-216.

HÜBNER, R., \& DRUEY, M. D. (2006). Response execution, selection, or activation: What is sufficient for response-related repetition effects under task shifting? Psychological Research, 70, 245-261. doi: 10.1007/s00426-005-0219-8

LAVIE, N. (2005). Distracted and confused?: Selective attention under load. Trends in Cognitive Sciences, 9, 75-82.

Liefooghe, B., Demanet, J., \& Vandierendonck, A. (2009). Is advance reconfiguration in voluntary task switching affected by the design employed? Quarterly Journal of Experimental Psychology, 62, 850-857. doi:10.1080/17470210802570994

Liefooghe, B., Vandierendonck, A., Muyllaert, I., VerbrugGen, F., \& VANneste, W. (2005). The phonological loop in task alternation and task repetition. Memory, 13, 550-560. doi:10.1080/ 09658210444000250

Lien, M.-C., \& Ruthruff, E. (2008). Inhibition of task set: Converging evidence from task choice in the voluntary task-switching paradigm. Psychonomic Bulletin \& Review, 15, 1111-1116. doi:10.3758/ PBR.15.6.1111
LogAn, G. D. (2007). What it costs to implement a plan: Plan-level and task-level contributions to switch costs. Memory \& Cognition, 35, 591-602.

LoGAN, G. D., \& Gordon, R. D. (2001). Executive control of visual attention in dual-task situations. Psychological Review, 108, 393-434. doi:10.1037/0033-295X.108.2.393

Mattler, U. (2003). Priming of mental operations by masked stimuli. Perception \& Psychophysics, 65, 167-187.

MAYr, U., \& BelL, T. (2006). On how to be unpredictable: Evidence from the voluntary task-switching paradigm. Psychological Science, 17, 774-780. doi:10.1111/j.1467-9280.2006.01781.x

MAYR, U., \& BRYCK, R. L. (2007). Outsourcing control to the environment: Effects of stimulus/response locations on task selection. Psychological Research, 71, 107-116. doi:10.1007/s00426-005-0039-x

Miller, E. K., \& Cohen, J. D. (2001). An integrative theory of prefrontal cortex function. Annual Review of Neuroscience, 24, 167-202. doi:10.1146/annurev.neuro.24.1.167

RAPOPORT, A., \& BudESCU, D. V. (1997). Randomization in individual choice behavior. Psychological Review, 104, 603-617.

SoEtens, E. (1998). Localizing sequential effects in serial choice reaction time with the information reduction procedure. Journal of Experimental Psychology: Human Perception \& Performance, 24, 547-568.

Stevens, M., Lammertyn, J., Verbruggen, F., \& VandierenDONCK, A. (2006). Tscope: A C library for programming cognitive experiments on the MS Windows platform. Behavior Research Methods, 38, 280-286.

Vandierendonck, A., De Vooght, G., \& Van der Goten, K. (1998) Does random time interval generation interfere with working memory executive functions? European Journal of Cognitive Psychology, 10, 413-442.

Verbruggen, F., \& Logan, G. D. (2008). Automatic and controlled response inhibition: Associative learning in the go/no-go and stopsignal paradigms. Journal of Experimental Psychology: General, 137 649-672. doi:10.1037/a0013170

Verbruggen, F., \& Logan, G. D. (2009). Automaticity of cognitive control: Goal priming in response-inhibition paradigms. Journal of Experimental Psychology: Learning, Memory, \& Cognition, 35, 13811388. doi: $10.1037 / \mathrm{a} 0016645$

Waszak, F., Hommel, B., \& Allport, A. (2003). Task-switching and long-term priming: Role of episodic stimulus-task bindings in taskshift costs. Cognitive Psychology, 46, 361-413. doi:10.1016/S0010 -0285(02)00520-0 


\section{APPENDIX}

The mean RTs and analyses are presented in Tables A1 through A4. Error rates were very low (Experiment $1=3.6 \%$; Experiment $2=3.1 \%$; Experiment $3=4.6 \%$ ) and were not further analyzed.

We analyzed the mean RTs of Experiments 1 and 2 with a repeated measures ANOVA with the factors load (no load vs. load), trial type, and task transition (task repetition vs. task switch). In both experiments, we found main effects of load [RT(no load $<\mathrm{RT}($ load)] and task transition [RT(repetition) $<\mathrm{RT}$ (switch)]. The main effect of trial type was also significant, indicating that repetitions of stimuli or shapes induced faster responses than did alternations. In Experiment 1, the interaction between trial type and task transition was reliable, indicating that the switch cost was smaller on stimulus repetitions than on stimulus alternations (see Allport \& Wylie, 2000). The interaction between load and task transition was significant, indicating that the switch cost was smaller in the load than in the no-load condition. A contrast showed that this was especially due to marginally slower task repetitions in the load than in the no-load condition $\left[F(1,23)=3.75, M S_{\mathrm{e}}=9,861, \eta_{\mathrm{p}}^{2}=.14\right]$ and not by faster switches $(F<1)$ (for similar results, see Liefooghe, Vandierendonck, Muyllaert, Verbruggen, \& Vanneste, 2005). In Experiment 2, the interaction between load and task transition was not significant. This difference between Experiments 1 and 2 is possibly due to the inclusion of stimulus repetitions in Experiment 1.

We analyzed mean RTs from Experiment 3 with a mixed ANOVA with the factors load, trial type (animacy vs. size vs. neutral stimulus set), task transition, and task. We found main effects of load [RT(no load) < RT(load)] and task transition $[\mathrm{RT}($ repetition $)<\mathrm{RT}($ switch)]. Also, the main effect of trial type was significant. Contrasts showed that responses to neutral stimuli were slower than responses to stimuli of the size stimulus set $\left[F(1,31)=17.12, M S_{\mathrm{e}}=18,931, \eta_{\mathrm{p}}^{2}=.36\right]$. The differences between neutral and animacy were not significant $\left[F(1,31)=1.61, M S_{\mathrm{e}}=34,019, \eta_{\mathrm{p}}^{2}=.05\right]$. The differences between animacy and size were not significant either $\left[F(1,31)=2.64, M S_{\mathrm{e}}=42,558, \eta_{\mathrm{p}}^{2}=.08\right]$. The interaction between trial type and task was significant, indicating that performing a task on a stimulus that is associated with that same task leads to better performance than does performing another task. Contrasts confirmed this for both the animacy $\left[F(1,31)=18.19, M S_{\mathrm{e}}=39,806\right.$, $\left.\eta_{\mathrm{p}}^{2}=.37\right]$ and size stimulus $\left[F(1,31)=17.43, M S_{\mathrm{e}}=21,759, \eta_{\mathrm{p}}^{2}=.36\right]$ sets, but not for the neutral stimulus $(F<1)$ set.

Table A1

Mean Response Times (in Milliseconds) As a Function of Load, Trial Type, and Task Transition for Experiments 1 and 2

\begin{tabular}{|c|c|c|c|c|c|c|c|c|}
\hline \multirow[b]{3}{*}{ Trial Type } & \multicolumn{4}{|c|}{ No Load } & \multicolumn{4}{|c|}{ Load } \\
\hline & \multicolumn{2}{|c|}{$\begin{array}{c}\text { Task } \\
\text { Repetitions }\end{array}$} & \multicolumn{2}{|c|}{$\begin{array}{c}\text { Task } \\
\text { Switches }\end{array}$} & \multicolumn{2}{|c|}{$\begin{array}{c}\text { Task } \\
\text { Repetitions }\end{array}$} & \multicolumn{2}{|c|}{$\begin{array}{c}\text { Task } \\
\text { Switches }\end{array}$} \\
\hline & $M$ & $S E$ & $M$ & $S E$ & $M$ & $S E$ & $M$ & $S E$ \\
\hline \multicolumn{9}{|c|}{ Experiment 1} \\
\hline Stimulus repetitions & 624 & 31 & 889 & 29 & 656 & 32 & 849 & 33 \\
\hline Stimulus alternations & 831 & 25 & 940 & 27 & 877 & 33 & 965 & 34 \\
\hline \multicolumn{9}{|c|}{ Experiment 2} \\
\hline Shape repetitions & 798 & 35 & 930 & 45 & 796 & 31 & 989 & 39 \\
\hline Shape alternations & 809 & 41 & 962 & 46 & 837 & 35 & 1,010 & 42 \\
\hline
\end{tabular}

Table A2

Mean Response Times (in Milliseconds) As a Function of Load, Trial Type, Task Transition, and Task for Experiment 3

\begin{tabular}{|c|c|c|c|c|c|c|c|c|c|c|c|c|c|c|c|c|}
\hline \multirow{4}{*}{$\begin{array}{l}\text { Stimulus } \\
\text { Type }\end{array}$} & \multicolumn{8}{|c|}{ No Load } & \multicolumn{8}{|c|}{ Load } \\
\hline & \multicolumn{4}{|c|}{ Task Repetitions } & \multicolumn{4}{|c|}{ Task Switches } & \multicolumn{4}{|c|}{ Task Repetitions } & \multicolumn{4}{|c|}{ Task Switches } \\
\hline & \multicolumn{2}{|c|}{$\begin{array}{c}\text { Animacy } \\
\text { Task }\end{array}$} & \multicolumn{2}{|c|}{ Size Task } & \multicolumn{2}{|c|}{$\begin{array}{c}\text { Animacy } \\
\text { Task }\end{array}$} & \multicolumn{2}{|c|}{ Size Task } & \multicolumn{2}{|c|}{$\begin{array}{c}\text { Animacy } \\
\text { Task }\end{array}$} & \multicolumn{2}{|c|}{ Size Task } & \multicolumn{2}{|c|}{$\begin{array}{c}\text { Animacy } \\
\text { Task }\end{array}$} & \multicolumn{2}{|c|}{ Size Task } \\
\hline & $M$ & $S E$ & $M$ & $S E$ & $M$ & $S E$ & $M$ & $S E$ & $M$ & $S E$ & $M$ & $S E$ & $M$ & $S E$ & $M$ & $S E$ \\
\hline Animacy & 974 & 52 & 1,063 & 62 & 1,155 & 52 & 1,233 & 62 & 1,000 & 52 & 1,165 & 68 & 1,233 & 55 & 1,327 & 77 \\
\hline Size & 1,042 & 58 & 1,006 & 62 & 1,145 & 46 & 1,091 & 39 & 1,138 & 63 & 1,066 & 50 & 1,286 & 59 & 1,140 & 55 \\
\hline Neutral & 1,054 & 59 & 1,112 & 69 & 1,228 & 54 & 1,177 & 43 & 1,097 & 58 & 1,137 & 53 & 1,244 & 51 & 1,267 & 59 \\
\hline
\end{tabular}


APPENDIX (Continued)

Table A3

Outcome of the ANOVAs Conducted on the Response Times for Experiments 1 and 2

\begin{tabular}{|c|c|c|c|c|}
\hline Factors & $M S_{\mathrm{e}}$ & $d f$ & $F$ & $\eta_{\mathrm{p}}^{2}$ \\
\hline \multicolumn{5}{|c|}{ Experiment 1} \\
\hline Load & 16,665 & 1,23 & 0.72 & .03 \\
\hline Trial type & 16,818 & 1,23 & $63.04^{*}$ & .73 \\
\hline Task transition & 30,245 & 1,23 & $42.59^{*}$ & .65 \\
\hline Load $\times$ trial type & 8,087 & 1,23 & 2.31 & .09 \\
\hline Load $\times$ task transition & 5,549 & 1,23 & $4.76^{*}$ & .17 \\
\hline Trial type $\times$ task transition & 7,083 & 1,23 & $28.73^{*}$ & .56 \\
\hline Load $\times$ trial type $\times$ task transition & 3,836 & 1,23 & 2.00 & .08 \\
\hline \multicolumn{5}{|c|}{ Experiment 2} \\
\hline Load & 31,502 & 1,23 & 1.67 & .07 \\
\hline Trial type & 4,213 & 1,23 & $7.89^{*}$ & .26 \\
\hline Task transition & 15,822 & 1,23 & $80.79^{*}$ & .78 \\
\hline Load $\times$ trial type & 1,901 & 1,23 & 0.55 & .02 \\
\hline Load $\times$ task transition & 4,970 & 1,23 & 3.88 & .14 \\
\hline Trial type $\times$ task transition & 4,059 & 1,23 & 0.00 & .00 \\
\hline Load $\times$ trial type $\times$ task transition & 2,700 & 1,23 & 1.89 & .08 \\
\hline
\end{tabular}

$* p<.05$.

Table A4

Outcome of the ANOVAs Conducted on the Response Times for Experiment 3

\begin{tabular}{lrrrr}
\hline \multicolumn{1}{c}{ Factors } & Wilks & $d f$ & \multicolumn{1}{c}{$F$} & $\eta_{\mathrm{p}}^{2}$ \\
\hline Load & .8501 & 1,31 & $5.47^{*}$ & .15 \\
Trial type & .6417 & 2,30 & $8.37^{*}$ & .36 \\
Task transition & .4100 & 1,31 & $44.60^{*}$ & .59 \\
Task & .9712 & 1,31 & 0.92 & .03 \\
Load $\times$ trial type & .9387 & 2,30 & 0.98 & .06 \\
Load $\times$ task transition & .9878 & 1,31 & 0.38 & .01 \\
Trial type $\times$ task transition & .8244 & 2,30 & 3.20 & .18 \\
Load $\times$ task & .9997 & 1,31 & 0.01 & .00 \\
Trial type $\times$ task & .4647 & 2,30 & $17.28^{*}$ & .54 \\
Task transition $\times$ task & .8849 & 1,31 & 4.03 & .12 \\
Load $\times$ trial type $\times$ task transition & .9999 & 2,30 & 0.00 & .00 \\
Load $\times$ trial type $\times$ task & .8751 & 2,30 & 2.14 & .12 \\
Load $\times$ task transition $\times$ task & .9992 & 1,31 & 0.03 & .00 \\
Trial type $\times$ task transition $\times$ task & .9959 & 2,30 & 0.06 & .00 \\
Four-way interaction & .8699 & 2,30 & 2.24 & .13 \\
\hline${ }^{*} p<.05$. & & & &
\end{tabular}

(Manuscript received August 21, 2009; revision accepted for publication December 22, 2009.) 